\title{
Study of concrete activation with IFMIF-like neutron irradiation: Status of EAF and TENDL neutron activation cross-sections
}

\author{
Mauricio García a , Patrick Sauvan, Raquel García, Francisco Ogando, and Javier Sanz \\ Power Engineering Department, UNED. Madrid, Spain
}

\begin{abstract}
The aim of this paper is to check the performance of last versions of EAF and TENDL libraries (EAF2007, EAF2010, and TENDL2014) in the prediction of concrete activation under the neutron irradiation environment expected in IFMIF, an accelerator-based neutron source conceived for fusion materials testing. For this purpose Activity and dose rate responses of three types of concrete (ITER-Bioshield kind, barite and magnetite concretes) have been studied.

For these quantities, dominant nuclides and production pathways have been determined and, then, a qualitative analysis of the relevant activation cross-sections involved has been performed by comparing data from mentioned libraries with experimental data from EXFOR database.

Concrete activation studies have been carried out with IFMIF-like neutron irradiation conditions using the ACAB code and EAF and TENDL libraries. The cooling times assessed are related to safety and maintenance operations, specifically 1 hour, 1 day and 12 days. Final conclusions are focused on the recommendations for the activation library to be used among those analyzed and cross-section data to be improved.
\end{abstract}

\section{Introduction}

An accurate prediction of the activation-related magnitudes is essential in order to plan safety and maintenance activities in fusion-related facilities. Previously to this paper, we have evaluated the reliability of the relevant activation cross-sections for the calculation of the Shutdown Dose Rate (SDDR) in ITER (International Thermonuclear Experimental Reactor) [1,2].

In the current work, we address a preliminary study focused on the status of the EAF 2007 [3], EAF 2010 [4] and TENDL 2014 [5] activation libraries for the concrete activation at the most exposed area of test cell area of IFMIF. The objective is to assess the reliability of these libraries in the prediction of the Activity and Contact Dose Rate (CDR) as well as to provide some recommendations about the most suitable library to be used in this facility for this kind of assessments.

After the methodology showed in Sect. 2, Sect. 3 is devoted to obtain major radionuclides and corresponding production pathways for the three concretes. Then, Sect. 4 analyzes the status of the activation cross-section data from EAF2007, EAF2010 and TENDL2014 libraries for the most relevant pathways by means of a comparison with experimental data from EXFOR [6] using JANIS [7] software. Finally, the conclusions of the Sect. 5 provide general recommendations about the activation library to be used for concrete activation in IFMIF as well as a list of the cross-sections to be updated with priority.

\section{Methodology and input data}

Concrete activation calculations under IFMIF-like neutron irradiation have been performed for three types of concrete

a e-mail: maurigarciac@ind.uned.es as possible candidates to be part of the test-cell shielding: ITER-bioshield kind, magnetite and barite concretes. The neutron flux used to activate the concretes has been calculated by the "Karlsruhe Institut für Technologie" (KIT) using Monte Carlo simulation [8] and is provided in 211 VITAMIN-J group structure. It corresponds to the flux calculated in concrete wall downstream in the IFMIF testcell during IFMIF nominal irradiation conditions $(125 \mathrm{~mA}$ of deuteron at $40 \mathrm{MeV}$ ); specifically, in a cube-shaped slab of $20 \mathrm{~cm}$ thickness in the direction of the accelerator beam and $50 \mathrm{~cm}$ of height, $50 \mathrm{~cm}$ of width.

The neutron flux spectrum is showed in Fig. 1. The maximum energy of the neutrons is around $55 \mathrm{MeV}$.

The composition of the concretes is given in Table 1.

Activation analysis is performed using the ACAB [9] activation code for 2-years continuous full power irradiation as a preliminary conservative approach, and the response functions (Activity and CDR) are evaluated at 1 hour, 1 day and 12 days after shutdown. From this calculation, we get major radionuclides (contributing at least $5 \%$ to Activity or CDR at some cooling time) and producing pathways (contributing at least $5 \%$ to the production of some major radionuclide).

Once we collect the pathways, in order to assess the reliability of the relevant activation cross-sections, our first approach was to use the EAF validation procedure for the EAF2007 activation library [10], and then, for those reactions not validated, to analyze possible improvements in EAF2010 and TENDL2014 libraries. However, all the spectra used for validation in [10] are quite different to our spectrum in both shape and maximum energy considered; additionally, for some of our cross section pathways Ref. [10] does not provide any quality mark. Therefore, we proceed by comparing directly data from activation libraries with the available differential

(C) The Authors, published by EDP Sciences. This is an Open Access article distributed under the terms of the Creative Commons Attribution License 4.0 (http://creativecommons.org/licenses/by/4.0/). 


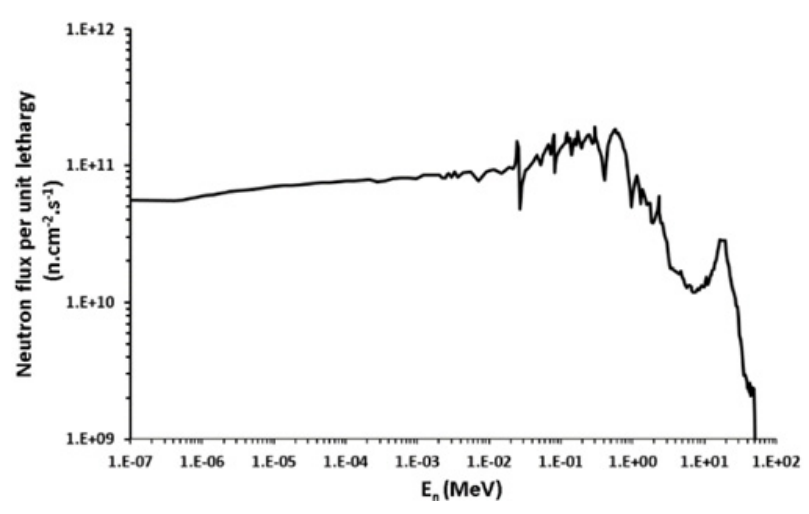

Figure 1. Neutron flux spectra used for activation calculations.

Table 1. Concretes composition in mass fraction.

\begin{tabular}{llll}
\hline & ITER-like & Barite & Magnetite \\
\hline $\mathbf{H}$ & 0,55 & 0,36 & 0,31 \\
$\mathbf{O}$ & 49,75 & 31,16 & 33,05 \\
$\mathbf{N a}$ & 1,71 & & \\
$\mathbf{M g}$ & 0,26 & 0,12 & 0,93 \\
$\mathbf{A l}$ & 4,69 & 0,42 & 2,35 \\
$\mathbf{S i}$ & 31,47 & 1,05 & 2,57 \\
$\mathbf{S}$ & 0,13 & 10,79 & 0,14 \\
$\mathbf{K}$ & 1,92 & 4,75 & \\
$\mathbf{C a}$ & 8,28 & 5,02 & 7,10 \\
$\mathbf{T i}$ & & & 5,43 \\
$\mathbf{V}$ & & & 0,31 \\
$\mathbf{C r}$ & & & 0,17 \\
$\mathbf{M n}$ & & & 0,20 \\
$\mathbf{F e}$ & 1,24 & & 47,43 \\
$\mathbf{B a}$ & & 46,34 & \\
Total & 100,00 & 100,00 & 100,00 \\
\hline & & &
\end{tabular}

experiments included in EXFOR database. Then, we summarize the conclusions about those reactions to be improved in the EAF and TENDL libraries as well as the most appropriate activation library to be used for the concrete activation simulations in the IFMIF test-cell.

\section{Main radionuclides and pathways}

This section is devoted to show the calculated major radionuclides contributing to Activity and CDR and their production pathways. For each of the two following tables (Table 2 for Activity and Table 3 for the CDR), first column provides radionuclide of interest and the production pathway for the three concretes. The following columns show radionuclide relevance $(\mathrm{X})$ or not (blank) for the three cooling times. It is worth noting that these two tables collect this information jointly for the three activation libraries used (EAF2007, EAF2010 and TENDL2014) since for each reaction the contribution to the response function using any of the 3 activation libraries is similar.

The activation calculations show 10 one-step reactions contributing to Activity and 12 reactions contributing to CDR. The minimum contribution considered as relevant for Tables 2 and 3 is $5 \%$.

Table 4 shows all the relevant pathways classified by $\%$ contribution whatever the activation library is used.

A total number of 7 reactions from Tables 2 and 3 contribute to the Activity or CDR below $20 \%$ and are not
Table 2. Dominant reactions contributing to the Activity.

\begin{tabular}{|c|c|c|c|}
\hline \multirow{2}{*}{ Reactions } & \multicolumn{3}{|c|}{ Contribution } \\
\hline & $1 \mathrm{~h}$ & $1 d$ & $12 \mathrm{~d}$ \\
\hline \multicolumn{4}{|l|}{ ITER-like concrete } \\
\hline$\overline{\mathrm{Na} 23(\mathrm{n}, \mathrm{g}) \quad \mathrm{Na} 24}$ & $X$ & $X$ & \\
\hline $\operatorname{Si} 30(n, g) \quad S i 31$ & $\mathrm{X}$ & & \\
\hline $\mathrm{Ca} 40(\mathrm{n}, \mathrm{a}) \quad \operatorname{Ar} 37$ & $X$ & $X$ & $\mathrm{X}$ \\
\hline $\mathrm{Ca} 44(\mathrm{n}, \mathrm{g}) \quad \mathrm{Ca} 45$ & & $\mathrm{X}$ & $\mathrm{X}$ \\
\hline \multicolumn{4}{|l|}{ Barite concrete } \\
\hline 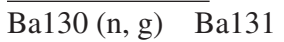 & $X$ & $X$ & $X$ \\
\hline Ba138 (n, g) Ba139 & $X$ & & \\
\hline $\mathrm{S} 32(\mathrm{n}, \mathrm{p}) \quad \mathrm{P} 32$ & $X$ & $\mathrm{X}$ & $X$ \\
\hline \multicolumn{4}{|l|}{ Magnetite concrete } \\
\hline $\begin{array}{ll}\mathrm{Fe} 54(\mathrm{n}, \mathrm{g}) & \mathrm{Fe} 55\end{array}$ & $\mathrm{X}$ & $X$ & $X$ \\
\hline $\operatorname{Mn} 55(\mathrm{n}, \mathrm{g}) \operatorname{Mn} 56$ & $\mathrm{X}$ & & \\
\hline $\mathrm{Fe} 56(\mathrm{n}, 2 \mathrm{n}) \quad \mathrm{Fe} 55$ & $X$ & $\mathrm{X}$ & $X$ \\
\hline $\mathrm{Ca} 40(\mathrm{n}, \mathrm{a}) \quad \operatorname{Ar} 37$ & & $\mathrm{X}$ & $X$ \\
\hline
\end{tabular}

Table 3. Dominant reactions contributing to the CDR.

\begin{tabular}{|c|c|c|c|c|}
\hline \multirow{2}{*}{ Reactions } & & \multicolumn{3}{|c|}{ Contribution } \\
\hline & & $1 \mathrm{~h}$ & $1 d$ & $12 \mathrm{~d}$ \\
\hline \multicolumn{5}{|c|}{ ITER-like concrete } \\
\hline $\mathrm{Na} 23(\mathrm{n}, \mathrm{g})$ & $\mathrm{Na} 24$ & $X$ & $\mathrm{X}$ & \\
\hline $\mathrm{Na} 23(\mathrm{n}, 2 \mathrm{n})$ & $\mathrm{Na} 22$ & & & $\mathrm{X}$ \\
\hline Fe58 $(\mathrm{n}, \mathrm{g})$ & $\mathrm{Fe} 59$ & & & $\mathrm{X}$ \\
\hline Fe54 $(n, p)$ & Mn54 & & & $\mathrm{X}$ \\
\hline $\mathrm{Fe} 56(\mathrm{n}, 2 \mathrm{np})$ & Mn54 & & & $X$ \\
\hline \multicolumn{5}{|c|}{ Barite concrete } \\
\hline $\operatorname{Ba130}(\mathrm{n}, \mathrm{g})$ & Ba131 & $\mathrm{X}$ & $\mathrm{X}$ & $\mathrm{X}$ \\
\hline $\mathrm{K} 41(\mathrm{n}, \mathrm{g})$ & $\mathrm{K} 42$ & $X$ & $\mathrm{X}$ & \\
\hline \multicolumn{5}{|c|}{ Magnetite concrete } \\
\hline Mn55 (n,g) & Mn56 & $\mathrm{X}$ & & \\
\hline $\mathrm{Fe} 56(\mathrm{n}, \mathrm{p})$ & Mn56 & $\mathrm{X}$ & & \\
\hline $\mathrm{Fe} 58(\mathrm{n}, \mathrm{g})$ & Fe59 & & $\mathrm{X}$ & $\mathrm{X}$ \\
\hline $\mathrm{Fe} 54(\mathrm{n}, \mathrm{p})$ & Mn54 & & $\mathrm{X}$ & $\mathrm{X}$ \\
\hline Fe56 (n,2np) & Mn54 & & $X$ & $\mathrm{X}$ \\
\hline $\operatorname{Al} 27(\mathrm{n}, \mathrm{a})$ & $\mathrm{Na} 24$ & & $X$ & \\
\hline Ti48 (n,p) & $\operatorname{Sc} 48$ & & $\mathrm{X}$ & \\
\hline $\operatorname{Mg} 24(n, p)$ & $\mathrm{Na} 24$ & & $\mathrm{X}$ & \\
\hline
\end{tabular}

considered in Table 4, that is: $\mathrm{Si30}(\mathrm{n}, \mathrm{g}) \mathrm{Si} 31, \mathrm{~S} 32(\mathrm{n}, \mathrm{p}) \mathrm{P} 32$, Fe56(n,2np)Mn54, Fe56(n,p)Mn56, A127(n,a)Na24, Ti48 (n,p)Sc48 and $\mathrm{Mg} 24(\mathrm{n}, \mathrm{p}) \mathrm{Na} 24$.

Now, for those pathways in Table 4 producing radionuclides with a contribution higher than $50 \%$ to Activity or CDR at some cooling time, a preliminary evaluation of the cross-section quality is performed comparing data from EAF2007, EAF2010 and TENDL2014 activation libraries with differential experiments from EXFOR using JANIS software.

\section{Status of the relevant activation cross-sections}

In this section, we plot cross-sections for the most relevant pathways in Table 4. Each of the following figures is dedicated to a specific reaction plotting together data from EAF2007, EAF2010 and TENDL2014 jointly with differential experiments from EXFOR. From each of the 
Table 4. Pathways producing radionuclides contributing more than $20 \%$ to Activity or CDR at some cooling time.

\begin{tabular}{cc}
\hline Pathway & $\begin{array}{c}\text { Maximum contribution to Activity } \\
\text { or CDR at some time (\%) }\end{array}$ \\
\hline Na23 (n,g) Na24 & $>80 \%$ \\
Ba130 (n,g) Ba131 & $>80 \%$ \\
Na23 (n,2n) Na22 & $50 \%-80 \%$ \\
Mn55 (n,g) Mn56 & $50 \%-80 \%$ \\
Fe54 (n,g) Fe55 & $50 \%-80 \%$ \\
K41 (n,g) K42 & $20 \%-50 \%$ \\
Ca40 (n,a) Ar37 & $20 \%-50 \%$ \\
Ca44 (n,g) Ca45 & $20 \%-50 \%$ \\
Fe54 (n,p) Mn54 & $20 \%-50 \%$ \\
Fe56 (n,2n) Fe55 & $20 \%-50 \%$ \\
Fe58 (n,g) Fe59 & $20 \%-50 \%$ \\
Ba138 (n, g) Ba139 & $20 \%-50 \%$ \\
\hline
\end{tabular}

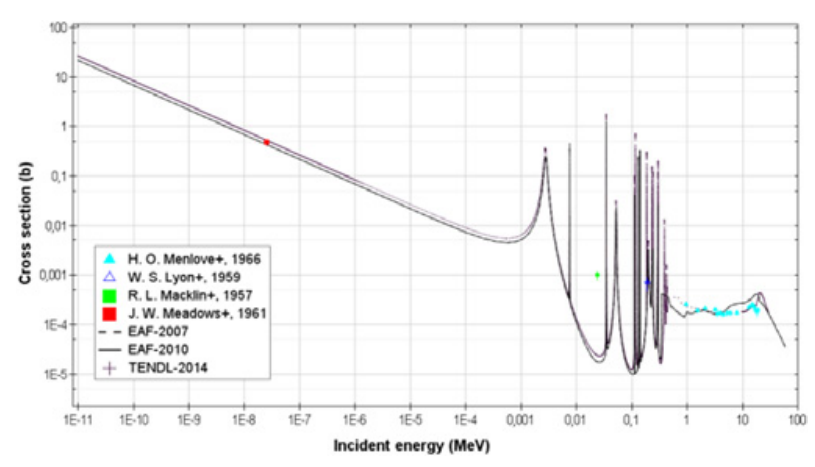

Figure 2. $\mathrm{Na} 23(\mathrm{n}, \mathrm{g}) \mathrm{Na} 24$.

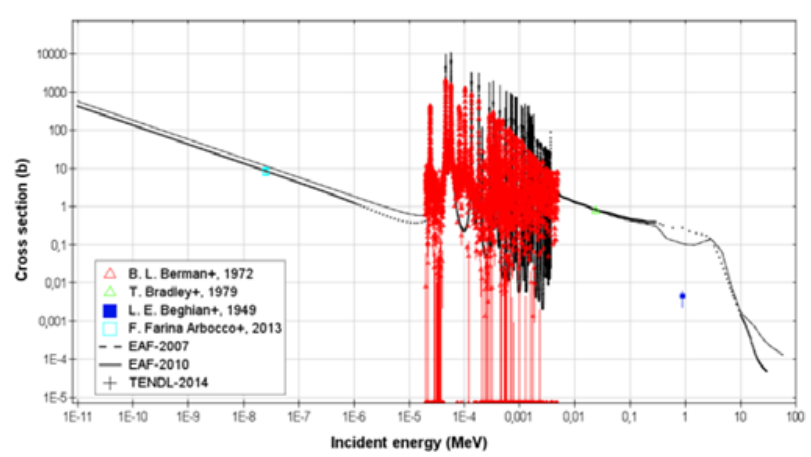

Figure 3. Ba130(n,g)Ba131.

figures we make some inferences about the quality status of the activation libraries and finally we provide a preliminary conclusion about the library to be used for the activation calculations in the IFMIF facility.

Figure 2 shows data related to $\mathrm{Na} 23(\mathrm{n}, \mathrm{g}) \mathrm{Na} 24$ reaction; we find an acceptable agreement between libraries themselves and with experimental data. However, there is a lack of differential experiments beyond $\sim 20 \mathrm{MeV}$ that would be convenient to solve.

For reaction $\mathrm{Ba} 130(\mathrm{n}, \mathrm{g}) \mathrm{Ba} 131$, which is showed in Fig. 3, we find again an overall good agreement among libraries except around $1 \mathrm{MeV}$ and beyond $10 \mathrm{MeV}$, where EAF2007 and EAF2010 are coincident but TENDL2014 show slight differences. Additionally, data from TENDL2014 are slightly lower than that from EAF versions at low energies. With regard to experimental data, we find a need for additional differential experiments for energies higher than $100 \mathrm{keV}$.

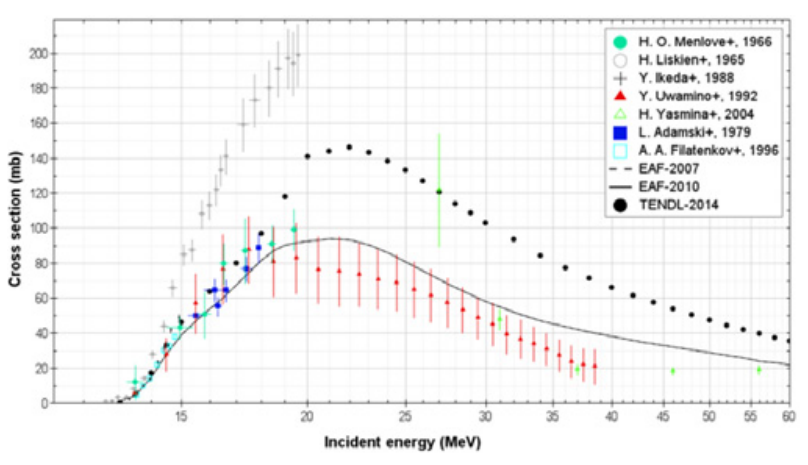

Figure 4. $\mathrm{Na} 23(\mathrm{n}, 2 \mathrm{n}) \mathrm{Na} 22$.

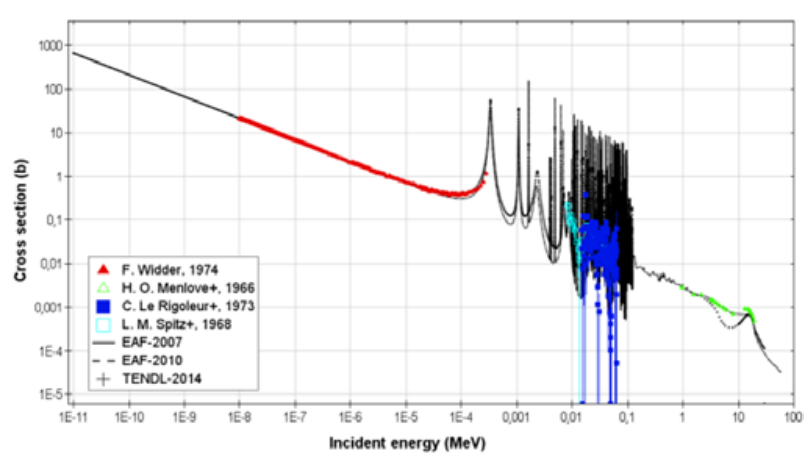

Figure 5. Mn55(n,g)Mn56.

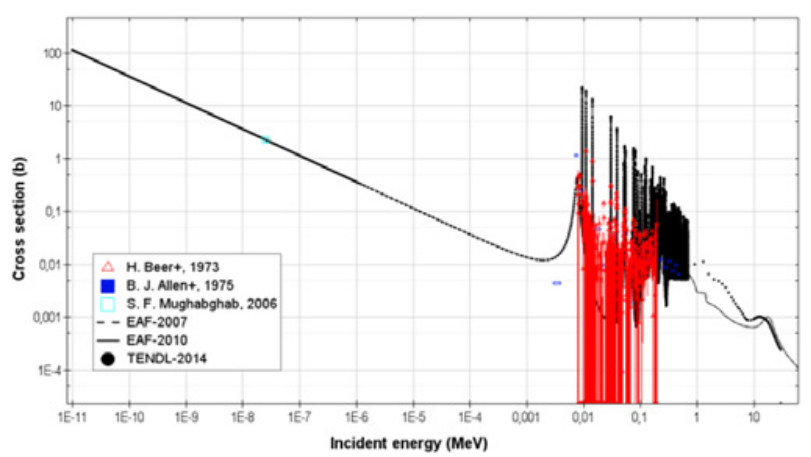

Figure 6. Fe54(n,g)Fe55.

From the Fig. 4 related to the $\mathrm{Na} 23(\mathrm{n}, 2 \mathrm{n}) \mathrm{Na} 22$ reaction, a disparity among experimental data is observed. We also notice differences between EAF versions and TENDL2014 in a factor up to $\sim 1.5$. Both disagreements induce a need for clarification of this reaction.

Figure 5 shows reaction Mn55(n,g)Mn56; we find very good agreement among libraries and differential experiments. As a minor matter, as in the case of the abovementioned $\mathrm{Na} 23(\mathrm{n}, \mathrm{g}) \mathrm{Na} 24$ reaction, additional experiments for energies higher than $\sim 20 \mathrm{MeV}$ would be convenient.

Finally, Fig. 6 shows Fe54(n,g)Fe55 reaction. Up to $1 \mathrm{MeV}$ we find an acceptable agreement between libraries and experimental data. However, for energies higher than $1 \mathrm{MeV}$ further work for improvement of libraries is advisable since there are discrepancies between EAFs and TENDL2014 and no differential experiments are available.

It is worth noting that no differences for these 5 relevant reactions are found between data from TENDL2014 and the last version TENDL2015; therefore, none of the improvements pointed out to be done for TENDL2014 version has been carried out yet. 
Two different aspects will be assessed in a future extension of this work. On one hand, data from EXFOR and libraries in the resonance region have not been compared, since the Doppler broadening effect is not taken into consideration for the evaluated data, which are produced at zero Kelvin. This comparison, after a modification of the library data by taking into account the broadening effect with the temperature, will be studied. On the other hand, this work did not deal with uncertainty data from the activation libraries. Both EAF and TENDL uncertainty data, when provided, as well as uncertainty from experimental data, will be used to analyze further validation of the library for the relevant reactions considered.

\section{Conclusions}

This work is focused on a preliminary assessment of the reliability of last versions of EAF and TENDL libraries when facing activation calculations for some candidate concretes in IFMIF, more specifically in the test cell area.

Firstly, using EAF2007, EAF2010 and TENDL2014 activation libraries, we calculate main radionuclides and producing pathways for Activity and CDR at 1 hour, 1 day and 12 days after shutdown. The analyzed concretes are ITER-bioshield kind, magnetite and barite, which are candidate materials for shielding showing significant differences in elemental composition.

A total number of 5 one-step pathways are found as relevant, that is, producing radionuclides contributing to Activity or CDR more than 50\% at some cooling time. These reactions, sorted according to the responsible activated concrete are: i) Na23(n,g)Na24 and $\mathrm{Na} 23(\mathrm{n}, 2 \mathrm{n}) \mathrm{Na} 22$ (coming from ITER-bioshield concrete), ii) $\mathrm{Ba} 130(\mathrm{n}, \mathrm{g}) \mathrm{Ba} 131$ (coming from barite concrete) and iii) Mn55(n,g)Mn56 and Fe54(n,g)Fe55 (coming from magnetite concrete). For these reactions, we have compared data from the libraries with experimental data from differential experiments.

For pathway $\mathrm{Na} 23(\mathrm{n}, \mathrm{g}) \mathrm{Na} 24$ we found acceptable reliability whereas for $\mathrm{Na} 23(\mathrm{n}, 2 \mathrm{n}) \mathrm{Na} 22$ further clarification of EAF and TENDL versions is required. In the case of $\mathrm{Ba} 130(\mathrm{n}, \mathrm{g}) \mathrm{Ba} 131$ we found a need for additional differential experiments beyond $100 \mathrm{keV}$ for clarification of the libraries at this energy range. Reaction Mn55(n,g)Mn56 is found as reliable but library data for pathway Fe54(n,g)Fe55 needs clarification for energies higher than $1 \mathrm{MeV}$.

Finally, as a preliminary recommendation about the library to be used for concrete activation calculations in the test cell area of IFMIF, we do not find a better option among those analyzed. EAF2007 and EAF2010 cross-sections are identical for the 5 pathways analyzed in detail and some differences are found compared to TENDL2014 (or TENDL2015) at some specific energy ranges of some reactions. Nevertheless, according to the available experimental data there are no rules to justify the utilization of any of them instead of the remainder.

This work was supported by Fusion for Energy (F4E), Barcelona, through the Specific Grant Agreement GRT-168.02. The views and opinions expressed herein reflect only the author's views. F4E and the Consortium on Nuclear Data and Analysis acknowledge the support by the Nuclear Energy Agency, Paris, in providing their services for the data file assembly and maintenance, and hosting the progress meetings.

\section{References}

[1] R. García, M. García, R. Pampin, J. Sanz. Status of reliability in determining SDDR for manual maintenance activities in ITER: quality assessment of relevant activation cross sections involved. Fusion Eng. Des. 112, 177-191 (2016)

[2] R. García, M. García, F. Ogando, R. Pampin, J. Sanz. Reliability of activation cross sections for estimation of shutdown dose rate in the ITER port cell and port interspace. These proceedings

[3] R.A. Forrest. The European Activation File: EAF2007 neutron-induced cross section library (2007)

[4] J.-Ch. Sublet, L.W. Packer, J. Kopecky, R.A. Forrest, A.J. Koning, D.A. Rochman. The European Activation File: EAF-2010 neutroninduced cross section library (2010)

[5] A.J. Koning et al. TENDL-2014: TALYS-based evaluated nuclear data library. www . talys . eu/tendl2014.html

[6] International Atomic Energy Agency. EXFOR: Experimental Nuclear Reaction Data (EXFOR) Database Version of 2016-07-01

[7] OECD-NEA. JANIS. Java-based Nuclear Data Information System. https://www.oecd-nea.org/ janis /

[8] P. Sauvan, M. García, R. García, J. Sanz, U. Fischer. Concrete activation analysis under IFMIF-like neutron irradiation. Deliverable GRT168.02-6D01

[9] J. Sanz, ACAB Activation Code for Fusion Applications: User's, Manual V5.0, Lawrence Livermore National Laboratory UCRLMA-143238, February (2000)

[10] R.A. Forrest, J. Kopecky, M. Pillon, A. Klix, S.P. Simakov, J.-Ch. Sublet, P. Bém, M. Honusek, E. imecková. Validation of EASY-2007 using integral measurements. UKAEA FUS 547 (2008) 